\title{
The stiff heart: Can we more safely navigate heart surgery?
}

\author{
James K. Kirklin, MD
}

\author{
From the Division of Cardiothoracic Surgery, and Department of Surgery, James and John Kirklin Institute for \\ Research in Surgical Outcomes (KIRSO), University of Alabama at Birmingham, Birmingham, Ala. \\ Disclosures: Author has nothing to disclose with regard to commercial support. \\ Received for publication Feb 22, 2018; accepted for publication Feb 22, 2018; available ahead of print March 22, \\ 2018. \\ Address for reprints: James K. Kirklin, MD, 1900 University Blvd, THT 760, Birmingham, AL 35294 (E-mail: \\ jkirklin@uabmc.edu). \\ J Thorac Cardiovasc Surg 2018;156:194-5 \\ $0022-5223 / \$ 36.00$ \\ Copyright $(2) 2018$ by The American Association for Thoracic Surgery \\ https://doi.org/10.1016/j.jtcvs.2018.02.060
}

In this issue of the Journal, Nguyen and colleagues ${ }^{1}$ have shed light on a corner of heart surgery that is often overlooked in surgical planning. Heart failure with preserved ejection fraction (HFpEF), which affects nearly half of the heart failure population, has become an important focus of heart failure cardiologists during the past 15 years. ${ }^{2}$ Diastolic dysfunction, the substrate of HFpEF, occurs in many individuals without the heart failure syndrome and is linked to multiple underlying conditions, such as hypertension, obesity, and diabetes. ${ }^{3}$ As the left ventricular stiffness progresses, heart failure symptoms emerge more commonly in elderly patients (cardiac senescence) and among sedentary patients. Regular exercise may retard progression of the disease, possibly through improved diastolic relaxation and adaptive changes in skeletal muscle and the peripheral vascular bed. ${ }^{4}$

Common pathophysiologic derangements include an increase in left ventricular afterload with hypertension or left ventricular outflow obstruction (inducing ventricular hypertrophy), a proinflammatory state seen in obesity and insulin resistance (causing abnormal cell signaling that promotes interstitial fibrosis), and diffuse coronary artery disease (promoting ischemia-induced impaired relaxation and fibrosis), all potentiating diastolic heart failure. ${ }^{5}$

An array of dysfunctional components contribute to symptomatology: impaired ventricular filling, increased passive stiffness, higher resting left atrial pressure with exaggerated response to stress, and limited ability to leverage the Frank-Starling mechanism with attempts to increase cardiac output. Although ejection fraction as a gross indicator of left ventricular function remains normal, systolic contraction can be quite deranged, with longitudinal contraction and wall motion abnormalities becoming more manifest with exertion. ${ }^{6}$ The diagnosis of HFpEF is often challenging, but it usually includes a constellation of imaging and laboratory findings plus

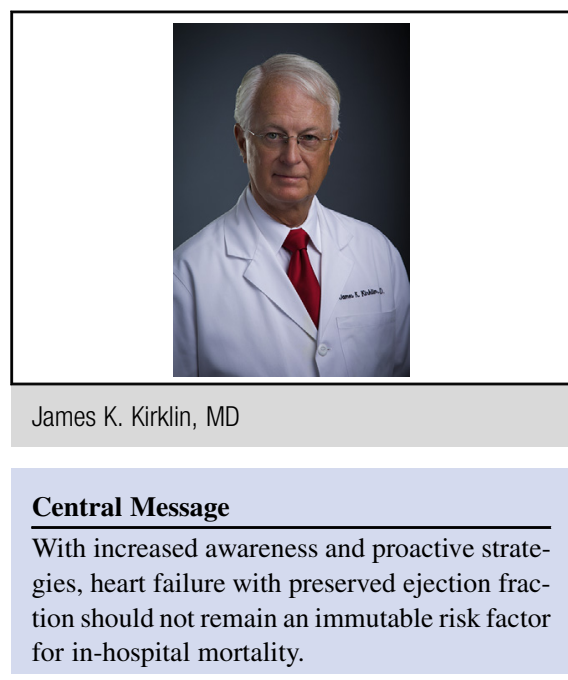

See Article page 188

heart failure symptoms. As would be expected, the diagnosis is initially suspected among patients with heart failure who are referred for echocardiographic evaluation, which typically reports abnormalities of isovolumetric relaxation, ventricular filling, and myocardial stiffness.

The incremental risk for in-hospital mortality and low cardiac output syndrome in such patients was the central finding of Nguyen and colleagues. ${ }^{1}$ In preparing patients with $\mathrm{HFpEF}$ for cardiac surgery, drugs that usually ameliorate heart failure with reduced ejection fraction (angiotensin converting enzyme inhibitors and $\beta$-blockers) are unfortunately largely ineffective in improving HFpEF. Furthermore, aggressive preoperative diuresis to reduce pulmonary congestion and end-organ edema is potentially dangerous in $\mathrm{HFpEF}$, because acute reduction in left ventricular filling pressure may cause an important reduction in cardiac input.

The initial surgical focus in such patients should be recognition of the condition, because there are important implications for intraoperative and postoperative management. Effective delivery of cardioplegia to optimize myocardial preservation is of paramount concern. Management of any aortic insufficiency during antegrade cardioplegia, strategies for cardioplegia delivery during coronary revascularization, and active decisions regarding myocardial temperature during aortic crossclamping may impact the prevention of unexpected postoperative low cardiac output syndrome. Understanding that effective cardiac output will require higher than usual filling pressures and 
that postoperative atrial fibrillation may be poorly tolerated may drive modifications of the usual management protocols. With increased awareness and proactive strategies, HFpEF should not remain an immutable risk factor for in-hospital mortality.

\section{References}

1. Nguyen LS, Baudinaud P, Brusset A, Nicot F, Pechmajou L, Salem JE, et al. Heart failure with preserved ejection fraction as an independent risk factor of mortality after cardiothoracic surgery. J Thorac Cardiovasc Surg. 2018;156:188-93.e2.
2. Owan TE, Hodge DO, Herges RM, Jacobsen SJ, Roger VL, Redfield MM. Trends in prevalence and outcome of heart failure with preserved ejection fraction. $N$ Engl J Med. 2006;355:251-9.

3. Witteles RM, Fowler MB. Insulin-resistant cardiomyopathy: clinical evidence, mechanisms, and treatment options. J Am Coll Cardiol. 2008;51:93-102.

4. Bhella PS, Hastings JL, Fujimoto N, Shibata S, Carrick-Ranson G, Palmer MD, et al. Impact of lifelong exercise "dose" on left ventricular compliance and distensibility. J Am Coll Cardiol. 2014;64:1257-66.

5. Aurigemma GP, Gaasch WH. Clinical practice: diastolic heart failure. $N$ Engl J Med. 2004:351:1097-105.

6. Yip G, Wang M, Zhang Y, Fung JW, Ho PY, Sanderson JE. Left ventricular long axis function in diastolic heart failure is reduced in both diastole and systole: time for a redefinition? Heart. 2002;87:121-5. 